\title{
Development of a solid phase extraction method for agricultural pesticides in large-volume water samples
}

\author{
Georges-Marie Momplaisir ${ }^{\mathrm{a}, *}$, Charlita G. Rosal ${ }^{\mathrm{a}}$, Edward M. Heithmar ${ }^{\mathrm{a}}$, Katrina E. Varner ${ }^{\mathrm{a}}$, \\ Lee A. Riddick ${ }^{a}$, David F. Bradford ${ }^{b}$, Nita G. Tallent-Halsell ${ }^{b}$
}

a U.S. Environmental Protection Agency, Office of Research and Development, National Exposure Research Laboratory, Environmental Chemistry Branch, P.O. Box 93478, Las Vegas, NV 89193-3478,United States

${ }^{\mathrm{b}}$ U.S. Environmental Protection Agency, Office of Research and Development, National Exposure Research Laboratory, Landscape Ecology Branch, P.O. Box 93478, Las Vegas, NV 89193-3478,United States

\section{A R T I C L E I N F O}

\section{Article history:}

Received 3 December 2009

Received in revised form 11 February 2010

Accepted 11 February 2010

Available online 18 February 2010

\section{Keywords:}

Solid phase extraction

Large-volume sampling

Pesticide

\begin{abstract}
A B S T R A C T
An analytical method using solid phase extraction (SPE) and analysis by gas chromatography/mass spectrometry (GC-MS) was developed to determine trace levels of a variety of 41 agricultural pesticides and selected transformation products in high-elevation surface waters. Large-volume water sampling (up to $100 \mathrm{~L}$ ) was employed because it was anticipated that pesticide contamination, if present, would be at very low levels. The target compounds comprise pesticides (and selected oxygen transformation products) known to have been extensively used in agriculture in the San Joaquin Valley, CA, USA. Solid phase extraction using the polymeric resin Abselut Nexus was optimized to extract the pesticide analytes from water samples. A single determinative method using GC-MS with electron ionization was used for all the analytes. Recoveries from $100 \mathrm{~L}$ of reagent water at $100 \mathrm{pg} / \mathrm{L}$ and $1 \mathrm{ng} / \mathrm{L}$ concentrations were generally greater than $75 \%$, although dimethoate, disulfoton, and phorate were not recovered. Analysis of the extracts without cleanup yielded detection limits for the remaining 38 analytes between 0.1 and $30 \mathrm{ng} / \mathrm{L}$. A silica cleanup with separate analysis of 3 eluant fractions improved detection limits for 37 of the compounds to between 6 and $600 \mathrm{pg} / \mathrm{L}$ in high-elevation surface waters.
\end{abstract}

Published by Elsevier B.V.

\section{Introduction}

Methods with well established performance are available for the determination of pesticides in fresh water at $\mathrm{ng} / \mathrm{L}$ levels. They often involve solid phase extraction (SPE) of about $1 \mathrm{~L}$ of water, followed by GC-MS with selected ion monitoring (SIM) [1,2]. Recently, advanced materials for SPE extraction have been investigated with separation by liquid chromatography and ultraviolet absorption detection (HPLC/UV) [3,4].

Over the past decade, interest has grown in the occurrence and distribution of pesticides and other organic pollutants in less impacted environmental waters, such as rainwater [5], snow and ice cores [6], and remote surface water bodies [7-9]. This interest has driven the development of more sensitive analysis methods, generally using one of three general approaches: improv-

\footnotetext{
is The United States Environmental Protection Agency funded the research described here. It has been subjected to agency review and approved for publication. Mention of trade names and commercial products does not constitute endorsement or recommendation for use.

* Corresponding author. Tel.: +1 702798 2255; fax: +1 7027982142

E-mail address: momplaisir.georges-marie@epa.gov (G.-M. Momplaisir).
}

ing sensitivity and selectivity of the determinative instrumental method, increasing the fraction of extracted target compound that is analyzed, or increasing the total volume of water extracted. Selectivity of GC-MS for pesticides with high electron affinities can be enhanced by using negative chemical ionization $(\mathrm{NCI})$, rather than the more common electron ionization (EI) [10]. Selectivity with either $\mathrm{NCI}$ or EI can be improved by the use of tandem mass spectrometry [11]

Microextraction can increase the fraction of extracted water sample analyzed. The most common variant of this approach is solid phase microextraction (SPME) using a fiber coated with polydimethylsiloxane [12]. Saraji and Esteki achieved detection limits in the low $\mathrm{ng} / \mathrm{L}$ range for derivatized carbamate pesticides using the single-drop liquid microextraction approach [13]. Derouiche et al. used headspace SPME with ion-trap MS/MS to detect as little as $0.4 \mathrm{ng} / \mathrm{L}$ of chlorinated pesticides in $2 \mathrm{~mL}$ of water [14]. Dispersive liquid-liquid microextraction (DLLME) was used by Berjani et al. to determine 13 pesticides at the low $\mathrm{ng} / \mathrm{L}$ level in $5 \mathrm{~mL}$ water [15]. DLLME uses a dispersing solvent to produce a suspension of about $5 \mu \mathrm{L}$ of dense organic extracting solvent in the water sample. The extracting solvent is separated by centrifugation and about $10 \%$ of the total volume is injected into the GC-MS. Reguiero et al. used ultrasonification to form similar dispersions and obtained low 
$\mathrm{ng} / \mathrm{L}$ detection limits for pesticides and musks in $10 \mathrm{~mL}$ of water [16]. Xiong and Hu compared DLLME to hollow fiber liquid phase microextraction for the determination of organosulfur pesticides [17].

Large-volume injection (LVI) can increase the fraction of extracted analyte to the GC. Almeida et al. analyzed $20 \mu \mathrm{L}$ of estuarine water extracts by LVI-GC-MS for 9 pesticides at low ng/L levels [18]. Sabik et al. injected $40 \mu \mathrm{L}$ of a $250-\mu \mathrm{L}$ SPE extract of water and obtained detection limits of $100-800 \mathrm{pg} / \mathrm{L}$ for 13 pesticides in river water [19].

Finally, large-volume water extraction can also increase sensitivity of pesticide determinations. Foster et al. used a Goulden liquid-liquid extraction system to sample or extract up to $120 \mathrm{~L}$ of water and obtained detection limits as low as $0.28 \mathrm{ng} / \mathrm{L}$ for lindane $[20,21]$. However, most large-volume water extractions use SPE due to its simplicity and ruggedness. Alegria and Shaw [22] used an XAD-2 SPE procedure originally employed by Ko and Baker [23] for the determination of polyaromatic hydrocarbons and polychlorinated biphenyls to analyze $76 \mathrm{~L}$ of sea water for sub-ng/L levels of triazine and organophosphate pesticides.

The large-volume water extraction method presented in this paper was developed for a study (Bradford et al., to be published) to evaluate the occurrence and temporal variation of airborne pesticides in high-elevation lakes of the Sierra Nevada Mountains in CA, USA. Previous researchers have established the occurrence of trace levels of a few current-use pesticides and several persistent discontinued organochlorine pesticides in multiple media in those mountains, presumably from airborne transport originating in the nearby Central Valley agricultural districts $[10,24,25]$. Recently, Usenko et al. developed a large-volume SPE method for 75 semivolatile compounds, including approximately 30 current-use pesticides and a variety of historic-use pesticides, as well as other persistent organochlorine compounds, in precipitation and surface water [26]. Using that method, Hageman et al. found chlorpyrifos and its oxon, dacthal (also known as DCPA), $\alpha$ - and $\beta$-endosulfan and their sulfate transformation products, and lindane, as well as four organochlorine compounds in snowpack at two sites in the Sierra Nevada [27].

The target analyte list for our method was 41 current-use pesticides (Table 1) of a wide range of polarities. The target detection limit range was less than $100 \mathrm{pg} / \mathrm{L}$. Microextraction methods have not been demonstrated for detection limits this low, nor have LVIGC methods on relatively low-volume extractions. Large-volume extraction was therefore chosen. Because of concerns regarding the use of organic solvents in a pristine environment, solid phase extraction was selected as the approach. Commercially available large-volume SPE devices $[22,23]$ were initially considered, but were too heavy and expensive for the field study that was planned. Therefore, a SPE method using a relatively small mass of functionalized polymeric resin was developed that was capable of extracting the analytes from $100 \mathrm{~L}$ of water in the field. Analyses of extracts were performed using GC-MS in EI mode. A silica cleanup with separate GC-MS analysis of three fractions was developed to improve detection limits.

\section{Experimental}

\subsection{Chemicals and reagents}

Mixed pesticide standards and internal standards for GC-MS analysis were purchased from Chem Services Inc. (West Chester, PA, USA). Organic solvents were obtained from Mallinckrodt and J.T. Baker (Phillipsburg, NJ). Working standards were prepared by appropriate dilution with Ultra Resi-Analyzed ${ }^{\circledR}$ grade ethyl acetate (ETAC). All standards were stored in a freezer at $-15^{\circ} \mathrm{C}$.
Table 1

Pesticides targeted in this study.

\begin{tabular}{|c|c|c|}
\hline Pesticide & CAS \# & Monitored ions ${ }^{\mathrm{a}}$ \\
\hline \multicolumn{3}{|l|}{ Aniline pesticides } \\
\hline Alachlor & $15972-60-8$ & $160,188,146,237$ \\
\hline Benfluralin & $1861-40-1$ & $292,264,276,318$ \\
\hline Ethalfluralin & $55283-68-6$ & $276,316,292,333$ \\
\hline Metolachlor & $51218-45-2$ & $162,238,240,146$ \\
\hline Pendimethalin & $40487-42-1$ & $252,281,162,253$ \\
\hline Trifluralin & $1582-09-8$ & $306,262,307,290$ \\
\hline \multicolumn{3}{|l|}{ Carbamate pesticides } \\
\hline Butylate & $2008-41-5$ & $217,146,156,174$ \\
\hline EPTC & $759-94-4$ & $189,128,132,86$ \\
\hline Pebulate & $1114-71-2$ & $203,128,132,161$ \\
\hline Carbaril & 63-25-2 & $144,115,116,145$ \\
\hline Carbofuran & $1563-66-2$ & $164,149,122,131$ \\
\hline \multicolumn{3}{|l|}{ OC pesticides } \\
\hline Chlorothalonil & $1897-45-6$ & $266,264,268,124$ \\
\hline Dicofol & $115-32-2$ & $251,139,253,111$ \\
\hline Endosulfan I & $959-98-8$ & $277,239,170,265$ \\
\hline Endosulfan II & $33213-65-9$ & $241,195,170,237$ \\
\hline Lindane & 58-89-9 & $217,181,183,219$ \\
\hline Permethrin I & $54774-45-7$ & $183,163,165,184$ \\
\hline Permethrin II & $51877-74-8$ & $183,163,165,184$ \\
\hline \multicolumn{3}{|l|}{ OP pesticides and oxons } \\
\hline Azinphos-methyl & $86-50-0$ & $160,132,104,161$ \\
\hline Chlorpyrifos & $2921-88-2$ & $314,197,199,316$ \\
\hline Chlorpyrifos oxon & $5598-15-2$ & $298,270,197,242$ \\
\hline Diazinon & $333-41-5$ & $304,137,179,152$ \\
\hline Diazoxon & $962-58-3$ & $273,137,288,260$ \\
\hline Dimethoate & $60-51-5$ & $87,93,143,229$ \\
\hline Disulfoton & $298-04-4$ & $88,142,186,274$ \\
\hline Fonofos & $944-22-9$ & $246,109,137,110$ \\
\hline Malaoxon & $1634-78-2$ & $127,99,109,125$ \\
\hline Malathion & $121-75-5$ & $173,125,127,93$ \\
\hline Methidathion & $950-37-8$ & $145,125,85,93$ \\
\hline Methyl parathion & $298-00-0$ & $263,109,125,79$ \\
\hline Methyl parathion oxon & $950-35-6$ & $247,109,230,200$ \\
\hline Phorate & $298-02-2$ & $75,121,260,231$ \\
\hline Phosmet & $732-11-6$ & $160,161,317,104$ \\
\hline Prophos & $13194-48-4$ & $242,158,139,200$ \\
\hline Tribufos & $78-48-8$ & $169,170,202,113$ \\
\hline \multicolumn{3}{|l|}{ Other pesticides } \\
\hline Cyanazine & $21725-46-2$ & $240,225,173,198$ \\
\hline DCPA & $1861-32-1$ & $301,299,303,332$ \\
\hline Linuron & $330-55-2$ & $248,61,187,160$ \\
\hline Simazine & $122-34-9$ & $186,173,158,203$ \\
\hline Napropamide & 15299-99-7 & $271,72,128,100$ \\
\hline Propargite & 2312-35-8 & $135,173,81,350$ \\
\hline
\end{tabular}

a Quantitation based on first $m / z$ listed.

Anhydrous, granular sodium sulfate (Tracepur) obtained from EM Science (Gibbstown, NJ) was baked in the oven at $400^{\circ} \mathrm{C}$ for $6 \mathrm{~h}$. Glasswool treated with dimethyldichlorosilane was purchased from Alltech Associates (Arlington Heights, IL). Solid phase sorbents: PPL (functionalized styrene-divinylbenzene polymer), Abselut Nexus [polystyrene crosslinked with 50\% divinylbenzene and poly(methylmethacrylate)] silica, and $\mathrm{C}_{18}$-funtionalized silica were obtained from Varian Inc. (Harbor City, CA). Amberlite XAD-2 (divinylbenzene-styrene copolymer) was purchased from Axys Environmental Systems Ltd. (Sidney, British Columbia, Canada). Polypropylene cartridges (12, 60 and $140 \mathrm{~mL}$ ) and matching polyethylene frits $(20-\mu \mathrm{m}$ pore size) were also purchased from Varian. Glass cartridges $(8 \mathrm{~mL})$ and PTFE frits (pore size $20-\mu \mathrm{m})$, used to prepare the silica columns, were obtained from Mallinckrodt Baker.

\subsection{Extraction and evaporation apparatus}

Large-volume water samples $(100 \mathrm{~L})$ were pumped in situ through the resin column using a ceramic, valveless pump ( $Q B$ 
pump, Q1CKC pump head; Fluid Metering Inc., Syosset, NY) powered by a $12 \mathrm{~V}$ and $12-\mathrm{A} \mathrm{h}$ battery. Lake and stream water samples were filtered on-line with a $142-\mathrm{mm}$ diameter, $0.7 \mu \mathrm{m}$ glass fiber filter (Whatman Inc., Florham Park, NJ) before extraction by the resin sorbent. All tubing was made of PTFE or PFA Teflon ${ }^{\mathrm{TM}}$. The column was attached to the sampling tubing by a laboratoryconstructed stainless steel bung fitting. A stainless steel Swagelok tee (Arizona Valve \& Fitting, Phoenix, AZ) fitted with a silicon septum (Supelco/Sigma-Aldrich, St. Louis, MO) was placed just before the column to allow analyte amendment of the water. Nonphosphate detergent solution (Micro 90, Cole-Parmer, Vernon Hills, IL), deionized water and HPLC grade methanol were used to clean the extraction assembly between sampling. The Turbo-Vap II and Turbo-Vap 500 used for evaporating eluants were purchased from Zymark (Hopkinton, MA).

\subsection{Extraction sorbent selection procedure}

Pre-cleaned sorbent material $\left(\mathrm{C}_{18}\right.$-functionalized silica, Amberlite XAD-2 resin, Bond Elut PPL, or Abselut Nexus) was obtained in bulk.

One liter reverse osmosis water (RO or reagent water) containing $5 \mu \mathrm{g}$ of each pesticide was passed through $2 \mathrm{~g}$ of each solid phase sorbent at a flow rate of $40 \mathrm{~mL} / \mathrm{min}$. Pesticide analytes were eluted with successive portions of $15 \mathrm{ml}$ each of n-hexane, n-hexane/ethyl acetate $(1: 1, v / v)$ and ethyl acetate. The excess water trapped in the resin was removed mainly in the n-hexane fraction. The aqueous layer was pipetted out of the n-hexane solvent, and extracted three times with $2-\mathrm{mL}$ portions of $\mathrm{n}$-hexane. The eluates and $\mathrm{n}$-hexane washes were combined and dried over anhydrous sodium sulfate, concentrated to $1 \mathrm{~mL}$ and solvent exchanged to ethyl acetate using the Turbo-Vap II evaporator at $30^{\circ} \mathrm{C}$ under a gentle stream of nitrogen.

\subsection{Final large-volume water extraction and analyte elution procedure}

All water extractions were conducted at approximately $250 \mathrm{~mL} / \mathrm{min}$ using $8 \mathrm{~g}$ of Nexus resin packed in the $140-\mathrm{mL}$ polypropylene syringe barrels. Reagent water and surface waters were used for recovery and method detection limit studies. Surface water samples were pumped in the field from one high-elevation (3091 m) lake and two lower elevation (500-900 m) streams in the southern Sierra Nevada.

Analyte recoveries in $100 \mathrm{~L}$ RO water samples were performed in triplicate and at two fortification levels ( $100 \mathrm{pg} / \mathrm{L}$ and $1 \mathrm{ng} / \mathrm{L})$. Surface water samples were collected in duplicate. After extraction, the Nexus columns were wrapped in baked aluminum foil and stored at $-25^{\circ} \mathrm{C}$ until elution. Prior to elution, resin columns were brought to room temperature and dried under ca. $0.5-\mathrm{L} / \mathrm{min}$ ultrapure nitrogen for at least $1 \mathrm{~h}$, until the resin was freeflowing and no evaporative cooling of the syringe barrel was noticeable. Analytes were eluted with $400 \mathrm{~mL}$ of dichloromethane (DCM) by gravity. The eluant was reduced to a final volume of ca. $1 \mathrm{~mL}$ at $23^{\circ} \mathrm{C}$ with the Turbo-Vap 500 closed cell concentrator and exchanged to n-hexane for silica cleanup as described in Section 3.2.3.

\subsection{Instrumentation}

All analyses were performed using an Agilent 6890 A capillary gas chromatograph and $5973 \mathrm{~N}$ mass selective detector (Agilent Technologies, Palo Alto, CA) using EI SIM mode. The gas chromatograph was fitted with a $30 \mathrm{~m} \times 0.25 \mathrm{~mm}$ ID fused silica capillary column coated with a $0.25-\mu \mathrm{m}$ film of crossbonded 5\% diphenyl-95\% dimethyl polysiloxane (Restek Corporation, Bellefonte, PA) with an integrated deactivated guard column of
$5 \mathrm{~m} \times 0.25-\mathrm{mm}$ ID fused silica. The injector used was a Gerstel CIS 4 inlet (Mühlheim, Germany), equipped with a programmable temperature vaporizer (PTV) and a $71 \mathrm{~mm} \times 2.0-\mathrm{mm}$ ID deactivated baffled liner. Pesticide-grade, deactivated, packed liner was initially investigated and found to be very susceptible to creating active sites. Sample extracts were introduced into the GC injector using a Gerstel MPS 2 autosampler equipped with a $10-\mu \mathrm{L}$ syringe.

A 1- $\mu \mathrm{L}$ sample was injected into the inlet liner in a pulsedsplitless mode. Ultrapure helium was used as carrier gas. The initial injector temperature was at $200^{\circ} \mathrm{C}$ and rapidly heated to $300^{\circ} \mathrm{C}$ (in approximately $8 \mathrm{~s}$ ). A pulsed pressure of $174 \mathrm{kPa}(25 \mathrm{psi}$ ) was applied during injection and held for $0.75 \mathrm{~min}$. After the initial pressure pulse, the carrier gas flow was held constant at $1 \mathrm{~mL} / \mathrm{min}$. The oven temperature program was: $50^{\circ} \mathrm{C}$ for $1 \mathrm{~min}, 35^{\circ} \mathrm{C} / \mathrm{min}$ to $150^{\circ} \mathrm{C}, 7^{\circ} \mathrm{C} / \mathrm{min}$ to $290^{\circ} \mathrm{C}, 100^{\circ} \mathrm{C} / \mathrm{min}$ to $300^{\circ} \mathrm{C}$, and held $1 \mathrm{~min}$. The total program required $24.96 \mathrm{~min}$. The ions listed in Table 1 were monitored in the SIM mode.

\section{Results and discussion}

\subsection{Sorbent selection}

The pesticide compounds (Table 1 ) exhibit a wide range of polarities $[28,29]$ however; they do not fall into the highly polar or the non-polar category. With this in mind, $\mathrm{C}_{18}$-functionalized silica, XAD-2, PPL and Abselut Nexus were chosen as potential solid phase sorbents. Preliminary extraction experiments were first conducted with $\mathrm{C}_{18}$-functionalized silica and XAD-2 solid phase sorbents. Recoveries were fair for most of the analytes, but somewhat variable, especially for the more polar compounds. PPL and Abselut Nexus yielded similar average recoveries: $95 \%$ and $97 \%$, respectively, for the analytes evaluated. Recoveries with Nexus were more consistent between compounds, with a standard deviation of $12 \%$, compared with $19 \%$ for PPL. In addition, Nexus was designed for extractions without the need for preconditioning with methanol, which is an advantage for field work. Therefore, Nexus was chosen for further evaluation, and no preconditioning was used after the initial solid phase comparison study.

\subsection{Development of the solid phase extraction procedure using Abselut Nexus}

After selecting Abselut Nexus as the most suitable sorbent for the target pesticides, an extraction procedure for large-volume water samples was developed and optimized. The complete extraction protocol is outlined in Fig. 1. Analyte amendment was performed using an injection port located just before the Nexus cartridge. A battery powered metering pump (Section 2.2) was used to deliver the large-volume water samples to the Nexus cartridges. The amount of resin necessary for optimum extraction of pesticide analytes from a $100 \mathrm{~L}$ water sample was determined by conducting a breakthrough experiment in which large-volume water samples amended with $5 \mu \mathrm{g}$ of each analyte were pumped through 8-g Nexus columns followed by 4-g Nexus columns. The cartridges were then separated and treated separately. For every analyte except dimethoate, the initial $8 \mathrm{~g}$ of resin recovered $>97 \%$ of the compound. The 8 -g column recovered $\sim 60 \%$ of the dimethoate.

\subsubsection{Solvent selection for analyte elution}

Recoveries by three elution procedures were evaluated: sequential 160 -mL volumes of $n$-hexane, $n$-hexane/ethyl acetate $(1: 1, v / v)$, and ethyl acetate (procedure 1 ); 400-mL of dichloromethane (procedure 2); and 400-mL acetone (procedure 3 ). The extracts from each procedure were solvent exchanged into $1 \mathrm{~mL}$ of ethyl acetate and analyzed by GC-MS to determine the recoveries for $5 \mu \mathrm{g}$ of each 


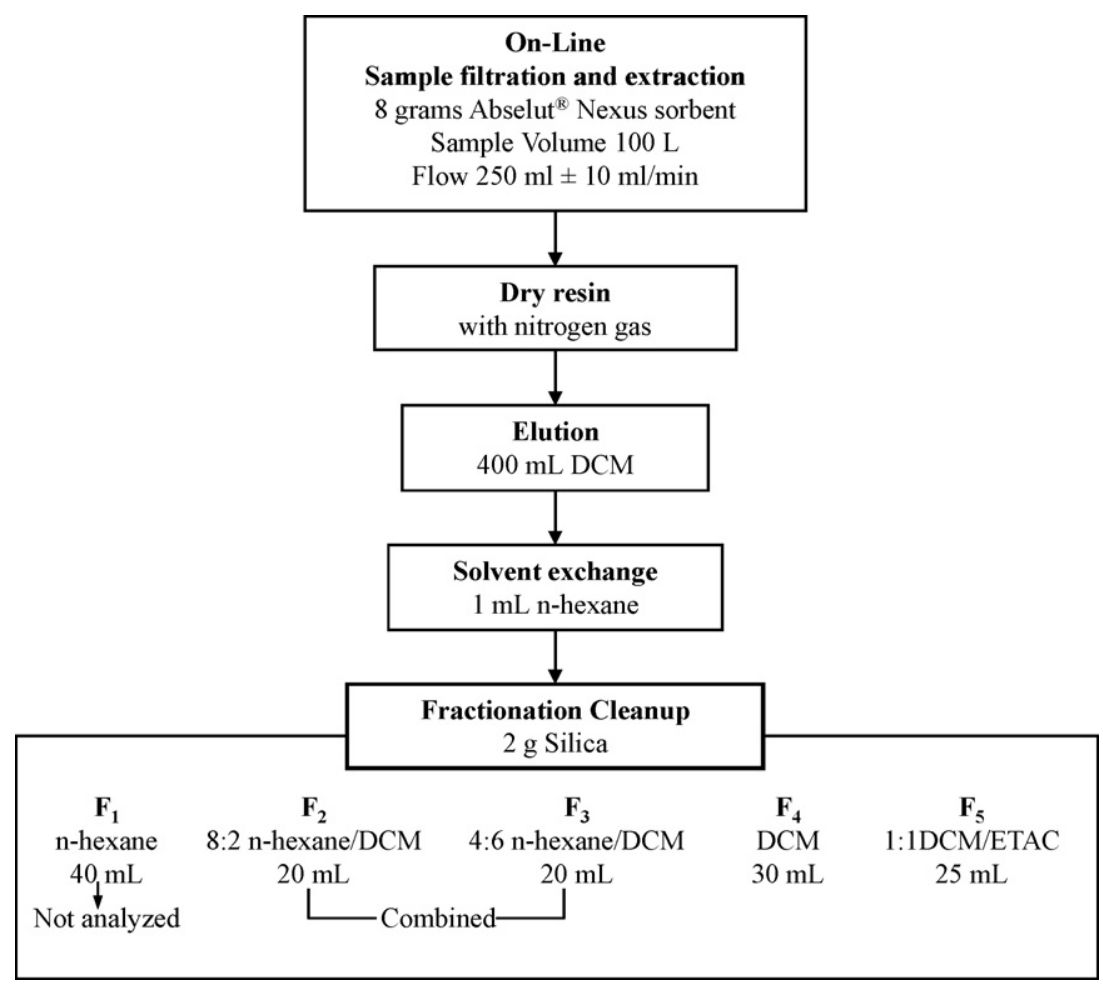

Fig. 1. Schematic for extracting and purifying water samples before GC-MS analysis.

pesticide. Dichloromethane provided higher recoveries on average ( $95 \%$ vs. $87 \%$ and $88 \%$ for the sequential hexane-ethyl acetate system and the acetone eluant, respectively) and more consistency among the analytes ( $8 \%$ vs. $12 \%$ and $18 \%$, respectively). Remaining experiments were therefore conducted with dichloromethane as the elution solvent.

\subsubsection{Sorbent drying and eluant evaporation temperature studies}

Initial analyte elutions were performed on extraction sorbents that had been briefly purged with nitrogen to remove excess moisture. In addition, the remaining water in the eluant required extensive drying with sodium sulfate. More complete removal of water from the sorbent with nitrogen without subsequent sodium sulfate drying was evaluated. One liter of reagent water, fortified with the suite of pesticide compounds ( $5 \mu \mathrm{g}$ each), was applied to each Nexus cartridge. Before elution using solvent procedure 1 , approximately $0.5 \mathrm{~L} / \mathrm{min}$ of nitrogen was passed through the extraction cartridges for drying periods of 60 and $150 \mathrm{~min}$. Passing $\mathrm{N}_{2}$ over the 8-g Nexus bed for $1 \mathrm{~h}$ removed almost all the water trapped in the resin. As shown in Fig. 2, there was little difference between those recoveries and the recoveries obtained after $2.5 \mathrm{~h}$ drying, except for the carbamates among which EPTC, butylate, and pebulate were the most affected. Recoveries improved for these analytes with the $2.5 \mathrm{~h}$ gas purge, after which the Nexus was visibly free flowing, indicating nearly complete water removal. Apparently, even small amounts of residual water affect GC analysis of the early-eluting analytes. As an added drying step, 300-mg sodium sulfate was added to the silica cleanup column in the final procedure.

The effect of solvent evaporation temperature was studied to see if evaporation time could be reduced. Duplicate samples of $400 \mathrm{~mL}$ of dichloromethane containing $5 \mu \mathrm{g}$ of each analyte were concentrated in the Turbo-Vap 500 apparatus at 23,35 and $58^{\circ} \mathrm{C}$. Fig. 2 shows the recoveries obtained for the three evaporation temperatures. Aside from the eight most volatile analytes (EPTC, butylate, pebulate, prophos, ethylfluralin, trifluralin, benfluralin, and phorate), there was no trend among the three temperatures for rest of the analytes. For the eight most volatile compounds analyzed,

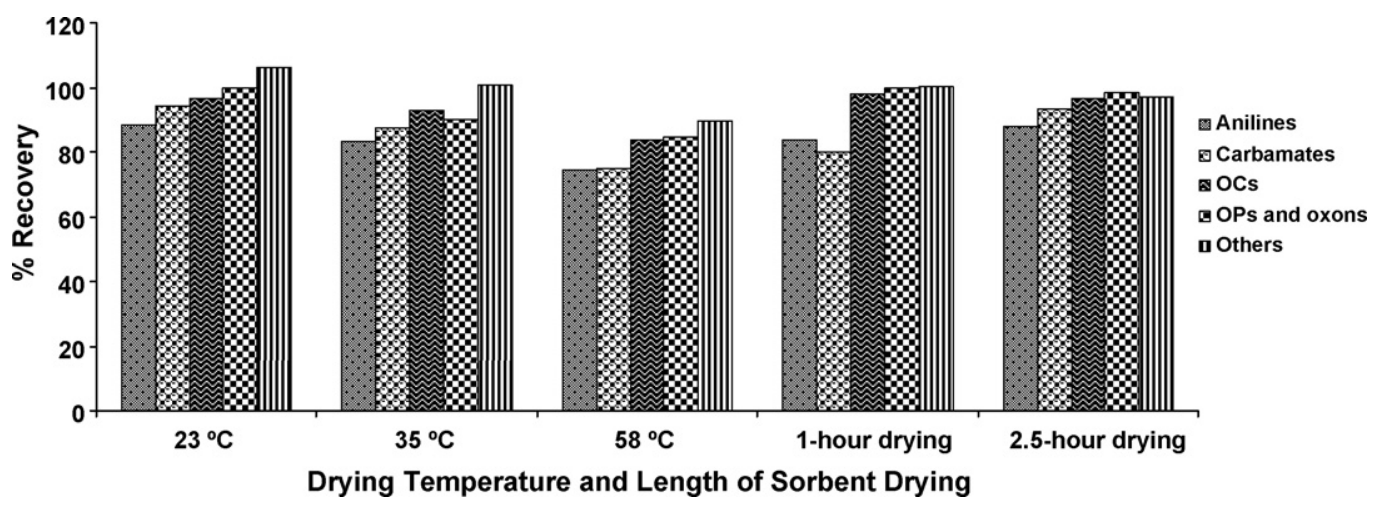

Fig. 2. Average recoveries of pesticide classes in various solvent evaporation temperatures and solid phase drying times. 
significant losses occurred at temperatures above $23^{\circ} \mathrm{C}$, and that temperature was used in the final method.

\subsubsection{Silica fractionation cleanup}

A multi-solvent cleanup on silica was developed to isolate the pesticide analytes from water matrix coextractants. The pesticides were eluted from the silica column based on increasing order of polarity and were collected in several solvent fractions (Fig. 1).

The initial elution with n-hexane removed polymer residues and other lipophilic matrix components but none of the target analytes. The pyrethroids (cis- and trans-permethrin), DCPA and most of the carbamate-, aniline-, and organochlorine-pesticides were eluted in the 8:2 and 4:6 n-hexane-dichloromethane fractions. Hexanedioic acid and other interfering compounds were collected in the dichloromethane fraction. The 1:1 DCM-ETAC solvent mixture eluted the organophosphate pesticides and oxygen analogues, leaving chlorophyll and other organics on the column.

\subsubsection{Holding time study}

We mentioned earlier, that the large-volume water extraction method was developed for a study to evaluate the occurrence and temporal variation of airborne pesticides in high elevation lakes of the Sierra Nevada Mountains in CA. Because of the remoteness of the sampling locations, it was anticipated that field samples may not be analyzed within the first days of collection but will be kept frozen to await analysis. The short term and long term stability of the pesticide analytes on the Nexus sorbent was then studied. This was performed using Nexus cartridges spiked with $5 \mu \mathrm{g}$ each pesticide in water. The wet cartridges were kept in a freezer at $-25^{\circ} \mathrm{C}$ and analyzed after 2, 15 and 30 days of storage. One of the samples was kept for 1 year. The recoveries obtained for a 2 day and 1-year-old samples are presented in Table 2. Prolonged storage of the Nexus cartridges did not affect the recovery of the majority of the pesticide compounds. The eluate from the 1-yearold sample extract was accidentally evaporated to dryness and reconstituted in ethyl acetate. Fractions of the more volatile species could have been lost during the evaporation process which could explain in part the lower recoveries obtained for butylate, ethalfluralin and pebulate. Recoveries for disulfoton and phorate were $50 \%$ and $66 \%$, respectively. These two compounds were later dropped in the study because of erratic recoveries in standard mixtures and sample extracts.

\subsubsection{Large-volume water extraction recoveries}

Pesticide analytes spiked into alpine lake water extracts and laboratory reagent waters were effectively recovered after silica cleanup. There was no significant difference between the alpine lake water matrices and the reagent water in the fractions analyzed.

Recoveries obtained with the final large-volume water analysis procedure were evaluated at both $100 \mathrm{pg} / \mathrm{L}$ and $1 \mathrm{ng} / \mathrm{L}$ analyte concentrations. Each amendment level was extracted in triplicate. The results, presented in Table 2, indicate average recoveries of $70-130 \%$ at both concentrations for 22 analytes. Eight compounds had moderately elevated recovery (130-150\%) at one of the concentrations. Azinphos-methyl and the oxygen analog of chlorpyrifos exhibited recoveries in excess of $150 \%$ and high variabilility at the higher amendment concentration. The three most volatile analytes (EPTC, butylate, and pebulate), as well as lindane and fonofos, gave lower recoveries (50-67\%), although the precision of the recovery was generally better than $10 \%$ (absolute standard deviation). This precision was similar for most of the analytes and indicated that determinations of these compounds could be useful, depending on data quality objectives. The oxygen analogs of azinphos-methyl and phosmet did not exhibit acceptable chromatographic sensitivity for analysis below $1 \mathrm{ng} / \mathrm{L}$, and they were deleted from the method. Recoveries for dimethoate, disulfoton, and phorate
Table 2

Pesticide recoveries from Nexus sorbents after short term and long term storage at $-25^{\circ} \mathrm{C}$.

\begin{tabular}{|c|c|c|}
\hline Pesticide & Stored-2 days & Stored -1 year \\
\hline \multicolumn{3}{|l|}{ Aniline pesticides } \\
\hline Alachlor & 108 & 106 \\
\hline Benfluralin & 84 & 76 \\
\hline Ethalfluralin & 88 & 57 \\
\hline Metolachlor & 109 & 111 \\
\hline Pendimethalin & 96 & 95 \\
\hline Trifluralin & 86 & 71 \\
\hline \multicolumn{3}{|l|}{ Carbamate pesticides } \\
\hline Butylate & 84 & 50 \\
\hline EPTC & 85 & 77 \\
\hline Pebulate & 92 & 64 \\
\hline Carbaril & 93 & 91 \\
\hline Carbofuran & $\mathrm{NA}^{\mathrm{a}}$ & NA \\
\hline \multicolumn{3}{|l|}{ OC pesticides } \\
\hline Chlorothalonil & 87 & 76 \\
\hline Dicofol & 82 & NA \\
\hline Endosulfan I & 100 & 97 \\
\hline Endosulfan II & 102 & 99 \\
\hline Lindane & 98 & 72 \\
\hline Permethrin $\mathrm{I}+\mathrm{II}$ & 96 & 90 \\
\hline \multicolumn{3}{|l|}{ OP pesticides and oxons } \\
\hline Azinphos-methyl & 116 & 97 \\
\hline Chlorpyrifos & 97 & 80 \\
\hline Chlorpyrifos oxon & 109 & 59 \\
\hline Diazinon & 106 & 94 \\
\hline Diazoxon & 106 & 94 \\
\hline Dimethoate & 69 & 72 \\
\hline Disulfoton & 102 & 52 \\
\hline Fonofos & 100 & 84 \\
\hline Malathion & 110 & 113 \\
\hline Methidathion & 111 & 78 \\
\hline Methyl parathion & 94 & 98 \\
\hline Methyl parathion oxon & 91 & 88 \\
\hline Phorate & 96 & 66 \\
\hline Phosmet & 103 & 95 \\
\hline Prophos & 105 & 105 \\
\hline Tribufos & NA & NA \\
\hline \multicolumn{3}{|l|}{ Other pesticides } \\
\hline Cyanazine & 114 & 110 \\
\hline DCPA & 98 & 87 \\
\hline Linuron & 130 & 118 \\
\hline Simazine & NA & NA \\
\hline Napropamide & 116 & 100 \\
\hline Propargite & 95 & 110 \\
\hline
\end{tabular}

were near zero at both concentrations. Interestingly, the results of the breakthrough experiment and sample holding time study, conducted at higher analyte concentrations, indicated incomplete retention only for dimethoate. The poor recoveries obtained for the three compounds at these lower concentrations indicate that the incomplete retention was not due to exceeding the capacity of the Nexus but rather to low partitioning of the analytes to the solid phase.

\subsection{Estimated method detection limits}

The instrument and method detection limits were determined as the concentrations at which the peak heights for the quantification ion and two other ions exceed $10 \sigma$ of the background at the analyte retention time, and the ratios of the qualifying ions to the quantification ion meet an intensity ratio criterion of $\pm 30 \%$. In addition, the retention time of the peak must match the expected retention time within $\pm 0.05 \mathrm{~min}$. Instrument detection limits were estimated in ethyl acetate. Method detection limits for reagent water were determined using pooled data of four 100 -L reverse osmosis water extractions. Method detection limits for surface 
Table 3

Pesticide recoveries at two concentrations from extraction of $100 \mathrm{~L}$ water, instrument detection limits and estimated method detection limits.

\begin{tabular}{|c|c|c|c|c|c|c|}
\hline & \multicolumn{2}{|c|}{ Recoveries } & \multirow[t]{2}{*}{$\mathrm{IDL}^{\mathrm{a}}$} & \multirow[t]{2}{*}{ MDL reagent water ${ }^{\mathrm{b}}$} & \multirow[t]{2}{*}{ MDL surface waters } & \multirow[t]{2}{*}{ MDL without cleanup } \\
\hline & $1 \mathrm{ng} / \mathrm{L}$ & $100 \mathrm{pg} / \mathrm{L}$ & & & & \\
\hline \multicolumn{7}{|l|}{ Aniline pesticides } \\
\hline Alachlor & $99 \pm 11$ & $94 \pm 11$ & 1.6 & 80 & 100 & 200 \\
\hline Benfluralin & $83 \pm 6$ & $91 \pm 6$ & 6 & 80 & 40 & 200 \\
\hline Ethalfluralin & $87 \pm 5$ & $78 \pm 3$ & 6 & 120 & 60 & 300 \\
\hline Metolachlor & $105 \pm 13$ & $111 \pm 5$ & 60 & 80 & 120 & 200 \\
\hline Pendimethalin & $90 \pm 10$ & $97 \pm 7$ & 8 & 200 & 140 & 3000 \\
\hline Trifluralin & $85 \pm 6$ & $90 \pm 7$ & 8 & 120 & 40 & 200 \\
\hline \multicolumn{7}{|l|}{ Carbamate pesticides } \\
\hline Butylate & $54 \pm 3$ & $61 \pm 6$ & 3 & 120 & 100 & 600 \\
\hline EPTC & $56 \pm 5$ & $57 \pm 5$ & 6 & 140 & 80 & 400 \\
\hline Pebulate & $67 \pm 7$ & $63 \pm 4$ & 4 & 60 & 60 & 200 \\
\hline Carbaril & $122 \pm 10$ & $138 \pm 10$ & 1.4 & 4 & $200^{c}$ & 3000 \\
\hline Carbofuran & $93 \pm 14$ & $82.1 \pm 0.2$ & 3 & 140 & 300 & 800 \\
\hline \multicolumn{7}{|l|}{ OC pesticides } \\
\hline Chlorothalonil & $75 \pm 7$ & $92 \pm 12$ & 2 & 30 & 14 & 60 \\
\hline Dicofol & $93 \pm 20$ & $110 \pm 27$ & 8 & 40 & 300 & 600 \\
\hline Endosulfan I & $77 \pm 14$ & $91 \pm 10$ & 2 & 40 & 30 & 800 \\
\hline Endosulfan II & $100 \pm 8$ & $96 \pm 6$ & 4 & 60 & 100 & 6000 \\
\hline Lindane & $60 \pm 9$ & $52 \pm 10$ & 3 & 120 & 100 & 600 \\
\hline Permethrin I & $99 \pm 4$ & $81 \pm 6$ & 3 & 40 & 40 & 1200 \\
\hline Permethrin II & $100 \pm 6$ & $80 \pm 5$ & 4 & 60 & 100 & 1200 \\
\hline \multicolumn{7}{|l|}{ OP pesticides and oxons } \\
\hline Azinphos-methyl & $185 \pm 30$ & $135 \pm 18$ & 16 & 300 & 300 & 1200 \\
\hline Chlorpyrifos & $82 \pm 5$ & $80 \pm 5$ & 2 & 30 & 20 & 200 \\
\hline Chlorpyrifos oxon & $206 \pm 56$ & $84 \pm 55$ & 8 & 140 & 80 & 200 \\
\hline Diazinon & $84 \pm 4$ & $99 \pm 11$ & 2 & 40 & 20 & 100 \\
\hline Diazoxon & $136 \pm 11$ & $112 \pm 8$ & 10 & 160 & 60 & 600 \\
\hline Dimethoate & $16 \pm 3$ & $\mathrm{NR}^{\mathrm{d}}$ & 14 & NR & NR & NR \\
\hline Disulfoton & Trace & $4 \pm 6$ & 16 & NR & NR & NR \\
\hline Fonofos & $52 \pm 4$ & $52 \pm 21$ & 2 & 80 & 100 & 140 \\
\hline Malaoxon & $127 \pm 19$ & $141 \pm 7$ & 10 & 400 & 400 & 1000 \\
\hline Malathion & $111 \pm 2$ & $96 \pm 4$ & 2 & 40 & 60 & 600 \\
\hline Methidathion & $94 \pm 10$ & $90 \pm 3$ & 8 & 300 & 600 & 16000 \\
\hline Methyl parathion & $102 \pm 14$ & $91 \pm 4$ & 1.4 & 30 & 30 & 300 \\
\hline Methyl parathion oxon & $140 \pm 21$ & $90 \pm 19$ & 18 & 100 & 80 & 1000 \\
\hline Phorate & NR & NR & 12 & NR & NR & NR \\
\hline Phosmet & $151 \pm 18$ & $113 \pm 13$ & 12 & 300 & 600 & 3000 \\
\hline Prophos & $93 \pm 6$ & $106 \pm 19$ & 4 & 120 & 80 & 160 \\
\hline Tribufos & $106 \pm 2$ & $93 \pm 8$ & 3 & 80 & 100 & 4000 \\
\hline \multicolumn{7}{|l|}{ Other pesticides } \\
\hline Cyanazine & $125 \pm 11$ & $146 \pm 13$ & 3 & $1000^{e}$ & $1000^{e}$ & $1000^{e}$ \\
\hline DCPA & $90 \pm 10$ & $91 \pm 2$ & 0.6 & 8 & 6 & 60 \\
\hline Linuron & $122 \pm 8$ & $99 \pm 6$ & 4 & 30 & 30 & 300 \\
\hline Simazine & $90 \pm 11$ & $111 \pm 9$ & 6 & 200 & 200 & 300 \\
\hline Napropamide & $126 \pm 7$ & $139 \pm 7$ & 1.4 & 30 & 30 & 700 \\
\hline Propargite & $117 \pm 12$ & $102 \pm 4$ & 20 & 300 & 400 & 30000 \\
\hline
\end{tabular}

anstrument detection limit, $\mathrm{pg} / \mathrm{L}$ injected.

b Method detection limit for $100 \mathrm{~L}$ water extraction, $\mathrm{pg} / \mathrm{L}$.

c Mass interference near retention time in many surface water extracts elevated detection limit.

d Not recovered or poorly recovered.

e Mass interference precludes reliable detection below ca. $1000 \mathrm{pg} / \mathrm{L}$.

waters were estimated from the pooled data of two high-elevation lakes and two low-elevation stream water extractions.

Estimated instrument detection limits (IDLs) ranged from 0.6 to $60 \mathrm{pg} / \mu \mathrm{L}$ (Table 3), and IDLs for 40 of 41 analytes were $\leq 20 \mathrm{pg} / \mu \mathrm{L}$. These correspond to $\leq 200 \mathrm{pg} / \mathrm{L}$ equivalent water concentration (a $1-\mu L$ GC-MS injection contains the analytes extracted from ca. $0.1 \%$ of the water sample, or $0.1 \mathrm{~L}$ of water). Oxygen analogs of organophosphate pesticides had generally higher IDLs than the parent compounds.

Method detection limits (MDLs) for reagent water and surface water averaged 100 and $140 \mathrm{pg} / \mathrm{L}$, respectively, for 37 of the $38 \mathrm{com}$ pounds that exhibited significant recovery. A large $m / z$ interference near the retention time of cyanazine limited reliable detection of that compound to concentrations exceeding about $1000 \mathrm{pg} / \mathrm{L}$ in all the samples.
The effectiveness of the fractionated silica cleanup procedure in reducing matrix interferences can be seen in Table 3 by comparing the MDLs for the reagent water and surface water with the MDLs in the last column estimated from the peak-to-peak noise of lake water extracts that were analyzed without fractionation of the cleanup eluants. The MDLs without cleanup are at least 3 times greater than those with cleanup for 31 of the 38 recovered compounds. MDLs for 16 analytes were improved by at least a factor of 10 by cleanup. The improvement in the MDL achieved by discarding some fractions of the silica cleaned extract is illustrated in Fig. 3 for the DCPA extracted from $100 \mathrm{~L}$ of lake water.

The detection limits obtained with this method were sufficient to conduct a large scale study to measure agricultural pesticides in four lakes at high elevation in Sequoia and Kings Canyon National Park which were selected to represent sites relatively near and far 


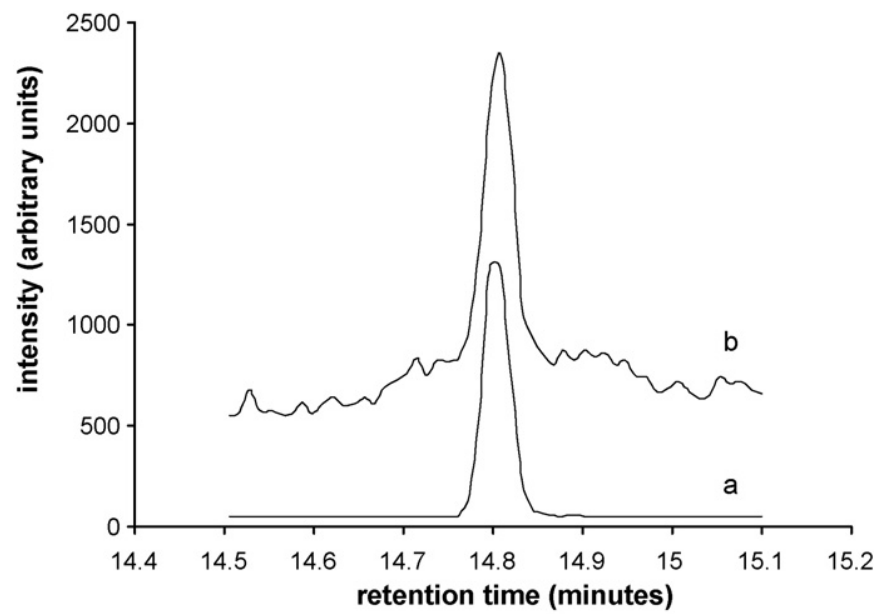

Fig. 3. Quantitation ion chromatogram at $(m / z$ 301) for DCPA of (a) combined fractions 2 and 3 of the extract of $100 \mathrm{~L}$ of alpine lake water after silica cleanup (as analyzed in final method), and (b) raw extract. DCPA concentration in lake water was approximately $50 \mathrm{pg} / \mathrm{L}$.

the San Joaquin Valley. Chlorothalonil, chlorpyriphos, DCPA, endosulfan I, endosulfan II, simazine and trifluralin were detected in multiple samples collected at these sites during June and October. Four of the compounds were found at concentrations and at frequencies that allowed the evaluation of temporal patterns (results of the temporal variation study are presented in a paper by Bradford et al., to be published).

\section{Conclusions}

The large-volume water extraction presented in this paper provides recoveries and detection limits sufficient to permit the detection of 38 of 41 targeted current-use pesticides and transformation products at concentrations at or below $500 \mathrm{pg} / \mathrm{L}$ in surface water. Detection of 29 analytes was possible at or below $100 \mathrm{pg} / \mathrm{L}$. Recoveries of four target compounds (azinphos-methyl, chlorpyrifos oxon, disulfoton and phorate) were poor, and those compounds are not suitable for analysis at $\mathrm{pg} / \mathrm{L}$ levels by this method. The detection limits reported here were suitable for our intended use, so no attempts were made to further lower them. However, about 20 of the 38 compounds recovered by this method yielded MDLs essentially unaffected by matrix in the cleaned-up analysis, as demonstrated by the agreement between the IDL and the MDL (Table 3). This indicates that either further reducing the final extract volume or using LVI-GC could significantly reduce those MDLs. Finally, alternative determinative methods to GC-MS, such as GC coupled with inductively coupled plasma mass spectrometry, could be investigated as a complementary technique for the analysis of phosphorus- and other heteroatom-containing pesticides.

This method is well suited to field studies of trace concentrations of 38 pesticides and degradates, covering a wide range of agricultural and domestic uses. It has superior detection limits to microextraction techniques used to improve sensitivity. It does not require the large volumes of organic solvent required for liquid-liquid extraction. The SPE resin used does not require the preconditioning needed with other solid phases, so there is no need for the use of organic solvents at environmentally sensitive sites. The method is particularly advantageous for sampling in remote locations accessible only on foot because the field extraction units are light. They are also inexpensive, facilitating parallel duplicate extractions. The field water extraction procedure is easily learned by sampling personnel with no chemistry background, and it can run unattended while other tasks are performed by the field teams. The fact that many analytes are stable on the resin for extended periods is advantageous for studies where resources or logistics result in long holding times. Finally, although saline waters were not examined in this study, the resin has been used for extraction of many diverse media. Therefore, it is likely the method could be applied to a broad range of environmental waters, including brackish, estuarine, or marine systems.

\section{Acknowledgements}

We are most grateful to Nellie Dujua and Pamela Pilger of the USEPA SEEP program for meticulously preparing the glassware and field extraction materials. We also thank Elizabeth Gentry, Patrick L. Ferguson, Tammy Jones-Lepp, Jason Scheick and Dr. Lantis Osemwengie for considerable help.

\section{References}

[1] S.D. Zaugg, M.W. Sandstrom, S.G. Smith, K.M. Fehlberg, U.S Geological Survey, Open-File Report 95-181, 1995, 49 pp.

[2] USEPA., EPA 815-R-05-005, April 2005

[3] S. Al-Degs, Yahya, A. Al-Ghouti, Mohammad, Int. J. Environ. Anal. Chem. 88 (2008) 487-498.

[4] N. Fontanals, R.M. Marce, P.A.G. Cormack, D.C. Sherrington, F. Borrull, J. Chromatogr. A 1191 (2008) 118-124.

[5] A. Malik, V.K. Singh, K.P. Singh, Bull. Environ. Contam. Toxicol. 79 (2007) 639-645.

[6] X.P. Wang, T.D. Yao, P.L. Wang, Y. Wei, L.D. Tian, Sci. Tot. Environ. 394 (2008) 134-143.

[7] E.M. Thurman, A.E. Cromwell, Environ. Sci. Technol. 34 (2000) 3079-3085.

[8] Z. Yao, G. Jiang, H. Xu, Environ. Pollut. 116 (2002) 49-56.

[9] J. Carroll, V. Savinov, T. Savinova, S. Dahle, R. McCrea, D.C.G. Muir, Environ. Sci. Technol. 42 (2008) 69-74.

[10] L.L. McConnell, J.S. LeNoir, S. Datta, J.N. Seiber, 17, Environ. Sci. Technol. (1998) 1908-1916, CODEN: ETOCDK ISSN:0730-7268. CAN 129:249930 AN 1998:634304 CAPLUS.

[11] E. Pitarch, C. Medina, T. Portoles, F.J. Lopez, F. Hernandez, Anal. Chim. Acta 538 (2007) 46-258.

[12] N. Sauret-Szczepanski, P. Mirabel, H. Wortham, Environ. Pollut. 139 (2006) 33-142.

[13] M. Saraji, N. Esteki, Anal. Bioanal. Chem. 391 (2008) 1091-1100.

[14] A. Derouiche, M.R. Driss, J.P. Morizur, M.H. Taphanel, J. Chromatogr. A 1138 (2007) 231-243.

[15] S. Berijani, Y. Assadi, M. Anbia, M.R. Milani, E. Aghaee, J. Chromatogr. A 1123 (2006) 1-9.

[16] J. Regueiro, M. Llompart, C. Garcia-Jares, J.C. Garcia-Monteagudo, R. Cela, J. Chromatogr. A 1190 (2008) 27-38.

[17] J. Xiong, B. Hu, J. Chromatogr. A 1193 (2008) 7-18.

[18] C. Almeida, P. Serodio, M.H. Florencio, J.M.F. Nogueira, Anal. Bioanal. Chem. 387 (2007) 2569-2583.

[19] H. Sabik, B. Rondeau, P. Gagnon, R. Jeannot, K. Dohrendorf, Int. J. Environ. Anal. Chem. 83 (2003) 457-468.

[20] G.D. Foster, P.F. Rogerson, Int. J. Environ. Anal. Chem. 41 (1990) 105-117.

[21] G.D. Foster, P.M. Gates, W.T. Foreman, S.W. McKenzie, F.A. Rinella, Environ. Sci. Technol. 27 (1993) 1911-1917.

[22] H.A. Alegria, T.J. Shaw, Environ. Sci. Technol. 33 (1999) 850-856.

[23] F.C. Ko, J.E. Baker, Mar. Chem. 49 (1995) 171-188.

[24] J.S. LeNoir, L.L. McConnell, G.M. Fellers, T.M. Cahill, J.N. Seiber, Environ. Toxicol. Chem. 8 (1999) 2715-2722.

[25] G.M. Fellers, L.L. McConnell, D. Pratt, S. Datta, Environ. Toxicol. Chem. 23 (2004) 2170-2177.

[26] S. Usenko, K.J. Hageman, D.W. Schmedding, G.R. Wilson, S.L. Simonich, Environ. Sci. Technol. 39 (2005) 6006-6015.

[27] K.J. Hageman, S.L. Simonich, D.H. Campbell, G.R. Wilson, D.H. Landers, Environ. Toxicol. Chem. 40 (2006) 3174-3180.

[28] A. Finizio, M. Vighi, D. Sandroni, Chemosphere 34 (1997) 131-161.

[29] U.S. Department of Agriculture, The ARS pesticide properties database, 2006, http://www.ars.usda.gov/Services/docs.htm?docid=14199. 